\title{
VARIAÇÕES DA SEGUNDA PESSOA NA TRADUÇÃO DE CHARMES DE PAUl VALÉRY
}

Álvaro Faleiros*
Roberto Zular* *

Resumo: Este artigo visa discutir algumas escolhas tradutórias envolvendo o uso dos pronomes tu e vous, nos poemas do livro Charmes, de Paul Valéry, que estamos traduzindo no momento. Nesta análise levamos em conta os diferentes usos dos pronomes pessoais em francês e em português, assim como as especificidades envolvidas em cada um dos poemas escolhidos neste artigo para ilustrar as escolhas. Quando possivel, comparamos as escolhas feitas por nós com as de outros tradutores.

Palavras-chave: Paul Valéry. Tradução poética. Pronomes pessoais.

\section{ENTRE TU E VOUS: UM PRIMEIRO PASSO}

$D$ ensar o sujeito do poema passa necessariamente pela questão de pensar a quem se endereça o poema. Sabemos com Benveniste que o "tu" é condição necessária para existência do "eu". É a partir dessa segunda pessoa, portanto, a partir do outro, que se configura a própria possibilidade de enunciação. No caso de Charmes de Paul Valéry, trata-se de um aspecto central para se compreender o modo como se elabora o complexo enunciativo ali em jogo. Nas páginas que seguem, nos propomos a refletir sobre essa variação a partir da segunda pessoa e de algumas de suas implicações no momento de traduzi-la para o português. Nesse sentido, pareceu-nos especialmente relevante orientar-nos pelos usos dos pronomes em português e em francês.

\footnotetext{
* Universidade de São Paulo (USP) - São Paulo - SP - Brasil. E-mail: alvarofaleiros@gmail.com

** Universidade de São Paulo (USP) - São Paulo - SP - Brasil. E-mail: rzular@usp.br
} 
Com efeito, uma das questões importantes que se colocam na tradução do francês para o português diz respeito aos pronomes pessoais. A dificuldade advém do fato de os usos nas duas línguas serem bastante distintos. Dentre as muitas diferenças, uma das que se destacam concerne precisamente os pronomes pessoais tu e vous. Em suas observações sobre o uso dos pronomes pessoais em francês, Cláudio Veiga (1974, p. 93) lembra que:

Os pronomes pessoais da segunda pessoa são, em francês, apenas tu $e$ vous, não existindo os chamados pronomes de tratamentos da língua portuguesa: Você, O Senhor, a Senhora, os Senhores, etc. Desse modo, os pronomes franceses tu e vous, bem como suas variações, poderão traduzir-se de vários modos.

$\mathrm{Na}$ breve síntese feita por Veiga, a primeira informação que salta aos olhos diz respeito ao modo de funcionamento dos pronomes de segunda pessoa na própria língua francesa, isto é, trata-se de um modo de operar, à primeira vista, organizado em torno de um par, diferentemente do que ocorre em português. Ainda que o vous, como aponta Patrick Charaudeau (1992, p. 154), possa substituir outras pessoas com o intuito de criar uma distância entre os interlocutores, seu uso costuma designar "explicitamente um interlocutor múltiplo nas mesmas condições que tu" ${ }^{1}$ (CHARAUDEAU, 1992, p. 123). Essa explicação vem acompanhada da seguinte observação:

$O$ vous [...] designa explicitamente um interlocutor único (ou múltiplo) nas mesmas condições que tu, quando o locutor se dirige a este com polidez [...] a noção de polidez corresponde a uma convenção social que varia de uma sociedade a outra, de um grupo social a outro, ou no interior do mesmo grupo. É possível que duas pessoas que não se conhecem se tratem por tu já num primeiro contato. Isso costuma ocorrer quando os indivíduos se reconhecem como pares e que as normas do grupo exigem que essa igualdade seja marcada (entre estudantes, em certos meios profissionais, ou comunidades religiosas, esportivas, etc.). Não é, pois, apenas a oposição tu/vous que marca a distância, a polidez ou seu contrário (CHARAUDEAU, 1992, p. 123-124).

Essa observação, ao destacar algumas exceções de uso, confirma a regra. Em francês, costuma-se marcar a proximidade ou distância entre os interlocutores pela escolha do pronome tu ou vous. Em um de seus mais conhecidos poemas, "Les pas", Paul Valéry explora precisamente esse jogo de proximidade e distanciamento.

\section{Les pas $^{2}$}

Tes pas, enfants de mon silence,

Saintement, lentement placés,

\footnotetext{
Todas as traduções são nossas, salvo indicação.

Como neste artigo partimos de análises do uso do pronome em francês, faz-se necessário apresentar no corpo do texto os poe mas em francês. Com o intuito de facilitar a leitura, incluímos, quando necessário, traduções semânticas, como a que segue: "Teus passos, crianças de meu silêncio,/ Santamente, lentamente pousados,/ Rumo ao leito de minha vigilância/ Procedem mudos e gelados.// Pessoa pura, sombra divina,/ Como são doces, teus passos retidos!/ Deus!... todos os dons que adivinho/ Vêm a mim sobre esses pés despidos!// Se, de teus lábios avançados,/ Preparas para apaziguar,/ Ao habitante de meus pensamentos/ O alimento de um beijo,// Não apresses essa atitude terna,/ Doçura de ser e não ser passo,/ Pois vivi de vos esperar,/ E meu coração era apenas vosso passo".
} 
Vers le lit de ma vigilance

Procèdent muets et glacés.

Personne pure, ombre divine,

Qu'ils sont doux, tes pas retenus!

Dieux !... tous les dons que je devine

Viennent à moi sur ces pieds nus!

Si, de tes lèvres avancées,

Tu prépares pour l'apaiser,

A l'habitant de mes pensées

La nourriture d'un baiser,

Ne hâte pas cet acte tendre,

Douceur d'être et de n'être pas,

Car j'ai vécu de vous attendre,

Et mon coeur n'était que vos pas.

Como se pode notar, o poema começa com o estabelecimento de uma relação de intimidade por meio do uso do "tu". A ação se dá inicialmente no presente, é o próprio ato da espera que se alonga e cria o estado de suspensão, de hesitação, que atravessa o texto. Esse andamento domina as três primeiras estrofes, em que a intimidade se evidencia pelo repetido uso da segunda pessoa do singular - qu'ils sont doux tes pas (Como são doces, teus passos); tes lèvres avancées (teus lábios avançados); tu prépares (preparas); - situação que culmina com o imperativo "ne hâte pas" (não apresses) com que começa a última estrofe. Nos dois últimos versos, temos uma mudança brusca: passamos do presente do ato que se anuncia para o passado da espera - j'ai vécu (vivi); mon coeur n'était que (meu coração era apenas). A distância no tempo é também marcada pronominalmente; ainda que o interlocutor pareça ser o mesmo, o tratamento que lhe é conferido é outro, pois é o vous que rege, no passado, a relação descrita no poema: j'ai vécu de vous attendre, (vivi de vos esperar); mon cœur n'était que vos pas (meu coração era apenas vosso passo).

Guilherme de Almeida, o primeiro a traduzir o poema entre nós, em sua antologia Poetas de França, preferiu ignorar esse jogo.

Os passos

Filhos do meu silêncio amante,

Teus passos santos e pausados,

Para o meu leito vigilante

Caminham mudos e gelados.

Que bons que são, vulto divino,

Puro ser, teus passos contidos!

Deuses!... os bens de meu destino

Me vêm sôbre êsses pés despidos. 
Se trazes, nos lábios risonhos,

Para saciar o seu desejo,

Ao habitante dos meus sonhos

$O$ alimento feliz de teu beijo,

Retarda essa atitude terna,

Ser e não ser, dom com que faço

Da vida a tua espera eterna,

E do coração o teu passo.

(ALMEIDA, 1965, p. 178)

Para o príncipe dos poetas pareceu ser mais importante garantir ao texto uma coerência interna, evitando esse estranhamento, ainda que, em francês, ele pareça ser revelador de uma tensão entre o ato que se anuncia e a situação pretérita existente entre o "eu" e o "tu". O jogo entre presente e passado, aliás, também é ignorado nessa tradução. Nelson Ascher, ao traduzir o poema, optou por conservar o tempo pretérito do final, ainda que, uma vez mais, tenha preferido ignorar a tensão pronominal que acompanha o jogo verbal.

O Passo

Teu passo, inato ao meu silêncio, beira sagradamente, a fio, meu leito insone e, com imenso vagar, vem vindo mudo e frio.

Sombra divina, forma pura:

Deus! tudo o que de bom supus - passo contido, que doçura! já se aproxima com pés nus.

Se, lábios entreabertos, frente a mim, reservar ao desejo faminto que me ocupa a mente este alimento que é teu beijo,

mantém o enlevo ainda à parte (no doce impasse existo e passo), pois, ao viver só de esperar-te, meu coração pôs-se em teu passo.

(ASCHER, 1990, p. 208)

Em nosso caso, pareceu-nos fundamental para o funcionamento do poema retomar o duplo distanciamento, temporal e relacional, que encerra o poema. Assim, para trazer ao leitor brasileiro essa operação textual, propomos a seguinte tradução: 
Os passos

Teus passos, meu silêncio cria, Santa e lentamente pousados

Ao leito da minha vigília

Procedem mudos e gelados.

Ente puro, vulto divino,

São doces teus passos contidos!

Deus! todos os dons que adivinho

Vem a mim sobre pés despidos!

Se com teu lábio em movimento

Vens acalmar este desejo

De quem me habita o pensamento

Com o alimento de um beijo,

Não apresses esta atitude terna,

Em doce ser e não ser passo,

Pois que vivi de vossa espera

E pus meu peito em vossos passos.

Ao evidenciar esse deslocamento da segunda pessoa, vemos o quanto o jogo com as posições pronominais no interior do poema ganha um sentido específico e, ao mesmo tempo, muda o lugar de leitura. O sujeito do enunciado se dobra sobre o sujeito da enunciação fazendo do "tu" e do "vós" uma encenação de um interlocutor mais próximo ou mais distante, e coloca o leitor como um ponto de intersecção entre essas duas posições. O poema se diz a alguém, singular, que o leitor torna plural somando sua experiência ao ato de leitura. Todo poema tem no mínimo um duplo endereçamento que em "Os passos" se torna constitutivo do próprio caminhar da enunciação. A hesitação entre os interlocutores, como forma amorosa, se torna a hesitação do ato poético. E do tu ao vós, ao leitor, o endereçamento passa do individual ao coletivo.

\section{"Pó́sie": entre A Boca e A Fonte}

No que concerne o uso do tu e do vous, outro momento interessante do livro Charmes é no poema intitulado "Poésie". Nele, há uma espécie de diálogo entre mãe e filho, de fato, entre uma "boca" que se alimentava no seio da Poesia (com P maiúsculo) e ela mesma, chamada de "Fonte" no final do poema. O diálogo se inicia assim:

Par la surprise saisie,

Une bouche qui buvait

Au sein de la Poésie

En sépare son duvet: 
- Ô ma mère Intelligence,

De qui la douceur coulait

Quelle est cette négligence

Qui laisse tarir son lait?

À peine sur ta poitrine,

Accable de blancs liens,

Me berçait l'onde marine

De ton cour chargé de biens;

À peine, dans ton ciel sombre,

Abattu sur ta beauté,

Je sentais, à boire l'ombre,

M'envahir une clarté!

Que traduzimos assim:

Tomada pelas surpresas

Uma boca que bebia

Separa as suas penas

No seio da Poesia:

- Ó minha mãe Inteligência,

Vem de ti o doce deleite,

Qual é essa negligência

Que deixa secar seu leite!

Teu peito mal me continha,

Opresso em brancos enleios;

Me embalava a onda marinha

De teu coração tão cheio;

Apenas, em teu céu turvo,

Abatido de beleza,

Sentia, sombra que sorvo,

Me invadir uma clareza!

O que importa sobretudo notar aqui é que a "boca" que se alimentava da mãe Inteligência dirige-se a esta usando o tu - ta poitrine (teu peito); ton cour chargé de biens (teu coração repleto), num claro sinal de proximidade. Como um filho clemente e queixoso dirigindo-se à mãe, a "boca" reclama que o leite que antes o alimentava (e ao próprio ato poético) agora não jorra mais. O lamento prossegue nesse estranho processo de personificação por mais algumas estrofes até que a "boca" chega a uma última queixa, que leva à pergunta final:

Immortelle, ta paupie re

Me refuse mes trésors, 
Et la chair s'est faite pierre

Qui fut tendre sous mon corps!

Des cieux même tu me sèvres,

Par quel injuste retour?

Que seras-tu sans mes lèvres?

Que serai-je sans amour?

Assim traduzida por nós:

Tua pálpebra, eterna,

Me recusa o meu tesouro,

E a carne que se fez pedra

Foi terna sob o meu corpo!

Por que injustos atalhos

Dos céus tu me desmamas?

O que serás sem meus lábios?

O que serei se não me amas?

A estrofe que segue e que encerra o poema é a resposta dada nos seguintes termos:

Mais la Source suspendue

Lui répond sans dureté:

- Si fort vous m'avez mordue

Que mon cour s'est arrêté!

No entanto, suspensa, a Fonte

Sem dureza retrucou:

- Me mordestes assim tão forte

Que meu coração parou!

Uma vez mais, a variação entre tu e vous tem um papel determinante no jogo textual. Ao dirigir-se à "boca" em tom mais formal, a "Fonte" claramente marca uma distância. No caso, a mordida da boca sedenta causou-lhe a parada do coração, impedindo-a de seguir na relação. Aqui também, como no poema "Os passos", a resposta se dá no tempo pretérito, enquanto o questionamento da "boca" se enuncia no tempo presente, produzindo um duplo distanciamento ao qual já nos referimos e que retomamos em nossa tradução.

\section{ENTRE "TU" E "VOCE"}

Outra questão que se coloca diz respeito à nossa escolha pela segunda pessoa do singular "tu" em vez da forma corrente "você". Maria Helena de Moura Neves (2000, p. 458), em sua Gramática de usos do português, quanto ao emprego dos pronomes pessoais, comenta: 
As formas VOCÊ e VOCÊS se referem à 2 a pessoa, mas levam o verbo para a 3 a pessoa, do mesmo modo como ocorre com os pronomes de tratamento VOSSA SENHORIA, VOSSA EXCELÊNCIA, O(A) SENHOR(A) [...] O emprego de VO$C \hat{E}$ é muito mais difundido do que o emprego de TU, para referência ao interlocutor. Além disso, ocorre frequentemente (embora mais especificamente em língua falada), que se usem formas de segunda pessoa em enunciados em que se emprega o tratamento VOC $\hat{E}$, de tal modo que se misturam formas de referência pessoal de segunda e de terceira pessoa [...].

Esse uso ocorre especialmente na conversação espontânea, e são abundantes os exemplos nos diálogos de peças teatrais: "Pode ditar o que VOCÊ quiser, eu escrevo. Sei fazer contas também. Eu já TE falei que meu nome é Érica?" (NEVES, 2000, p. 458).

Essa variação de uso pode, em grande medida, ser explicada pelo fato de, ao se concordar os pronomes pessoais átonos com a terceira pessoa do singular, cria-se uma enorme ambiguidade, o que, no uso corrente, costuma-se evitar.

No caso da tradução dos poemas supracitados, optamos pela manutenção do "tu", primeiramente com o intuito de marcar claramente a passagem para o "vós", cuja função nos pareceu ser determinante no modo de significar do poema. Além disso, o uso do "você" abriria espaço para uma série de ambiguidades que poderiam vir a criar opacidades consideráveis, para nosso projeto tradutório, desnecessárias. Deve-se ainda considerar o fato de que Paul Valéry não é exatamente um poeta que se identifica com o grau de informalidade que se encontra em diálogos de teatro.

Diante do exposto, ao longo do livro, preferimos, para manter certo ar solene, traduzir em geral o tu pela segunda pessoa do singular. Nossa tradução do poema "Palme" ilustra bem essa escolha. Nesse poema, que encerra o livro Charmes, se estabelece um diálogo entre o sujeito que enuncia e a árvore. Ao se dirigir a ela, o "eu" do poema usa o pronome tu. Trata-se ali de descrever toda a abjuração e paciência da árvore que aceita se submeter às maiores adversidades, assim como o poeta que, à época, atravessava a Primeira Guerra Mundial. O longo poema termina com a seguinte estrofe:

Qu'un peuple à présent s'écroule,

Palme!... irrésistiblement!

Dans la poudre qu'il se roule

Sur les fruits du firmament!

Tu n'as pas perdu ces heures

Si légère tu demeures

Après ces beaux abandons;

Pareille à celui qui pense

Et dont l'âme se dépense

À s'accroître de ses dons!

E que traduzimos como segue:

Que um povo pereça agora,

Ó Palma!... Ninguém resiste! 
Na poeira em que ele rola

Sobre o seu fruto celeste!

Não perdeste essas horas

Se leve tu te demoras

Nesses belos abandonos;

Igual àquele que pensa

E cuja alma se dispensa

A crescer com esses seus dons!

É certo que poderíamos ter procurado alguma solução com "você", como traduzir "Si légère tu demeures" por "Se leve você permanece". Ainda que não tenha sido a principal razão dessa retomada, pode-se logo notar que a conjugação do verbo nos permitiu a bela rima "demoras / horas". Mas, como dissemos anteriormente, o principal motivo de nossa escolha se deve ao fato de a dramaticidade que permeia a poética de Paul Valéry não ser atravessada pela coloquialidade, motivo pelo qual retomamos de modo sistemático ao longo do livro Charmes a segunda pessoa do singular. Essa escolha que norteou a tradução do tu impôs-se, contudo, com menos força em poemas em que o vous é a forma de tratamento dada ao interlocutor. Nesses casos, cada poema exigiu de nós uma reflexão, ainda que sempre atenta à coerência do conjunto dos poemas que formam, de fato, um livro.

\section{A voz ou o "vós" DE DEus}

Diferentemente do que ocorre em "Os passos" ou em "Poesia", poemas nos quais a segunda pessoa do plural surge no final dos poemas, há no livro Charmes um longo poema em que a presença do vous chamou-nos especialmente atenção. Com efeito, um dos mais imponentes poemas do livro, "Ébauche d'un serpent", tem a peculiaridade de, em seus 310 versos, ser o único em que Valéry se aprofunda em um tema bíblico. Trata-se, mais precisamente, da "retomada do mito da queda do paraíso por um jogo de perspectivas a partir da serpente" (ZULAR, 2014, p. 221). Nesse jogo enunciativo, a serpente ironicamente se dirige a Deus, por exemplo, nos seguintes termos:

Objet radieux de ma haine,

Vous que j'aimais éperdument,

Vous qui dûtes de la géhenne

Donner l'empire à cet amant,

Regardez-vous dans ma ténèbre!

Devant votre image funèbre,

Orgueil de mon sombre miroir,

Si profond fut votre malaise

Que votre souffle sur la glaise

Fut un soupir de désespoir! $!^{3}$

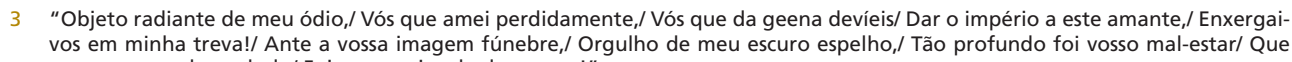
vosso sopro sobre o lodo/ Foi um suspiro de desespero!". 
Vale lembrar que, ainda que esteja em desuso no português, o pronome "vós" segue marcando o estilo solene, sobretudo se usado em preces e orações. Francisco Borba (2004, p. 1443-1444), em seu Dicionário do português contemporâneo, destaca dois usos principais: "1. usado para dirigir-se respeitosamente à pessoa a quem se fala [...]; 2. usado, em preces ou invocações, para dirigir-se a Deus". Num poema em que o diálogo se dá em tom de invocação optamos por traduzir a estrofe anterior como segue:

De meu ódio objeto radiante,

Vós que amei de forma extrema,

Vós que devíeis da geena

Dar o império a este amante,

Enxergai-vos em meu ser lúgubre!

Ante a vossa imagem fúnebre,

Orgulho de meu escuro espelho,

O mal-estar vos tomou todo

E vosso sopro sobre o lodo

Foi suspirar de desespero!

Essa não é a única estrofe em que se encontra o vous. Em todas elas optamos por retomar as mesmas ocorrências, fazendo o mesmo com as estrofes escritas originalmente na segunda pessoa do singular pelo motivo elencado anteriormente: como não usar o "vós" numa invocação em que a serpente dialoga com Deus?

Se, como dissemos, há uma certa estranheza no uso do "vós" em português, essa estranheza ajuda a marcar o tom ao mesmo tempo sagrado e profano do poema. O "vós" aparece ao mesmo tempo atribuindo um lugar de subserviência a Deus e transformando ironicamente essa subserviência em irresignação. O tom majestático vai sendo corroído pela tristeza do ser todo poderoso, pela onipotência do nada e, sobretudo, pelo deslocamento da enunciação que da boca da serpente se espraia pelo mundo. Aliás, não se trata de um tom, mas de vários, dificílimos de serem repropostos em português. O modo de endereçamento constitui a posição do sujeito que fala, o que nos obrigou, em alguns casos, a optar por traduções menos evidentes dos pronomes.

\section{VAMOS COM "VOCÊS"}

Um dos poemas em que o uso do vous nos levou a escolhas, digamos, menos ortodoxas, foi "Fragments du Narcisse". Escrito originalmente em alexandrinos, é provavelmente um dos mais enigmáticos poemas de Valéry. Isso se deve, em certa medida, a seu caráter fragmentário; fragmentação e movência que, segundo Júlio Castañon Guimarães, estaria ligada à própria "instabilidade da figura de Narciso" (in VALÉRY, 2013, p. 27). Envolvendo o leitor num clima onírico, logo no início do poema, após correr no bosque, Narciso cai diante de uma fonte, contempla sua imagem e pede às Ninfas que não perturbem sua contemplação com o seguinte tom:

Nymphes! si vous m'aimez, il faut toujours dormir!

La moindre âme dans l'air vous fait toutes frémir; 
Même, dans sa faiblesse, aux ombres échappée,

Si la feuille éperdue effleure la napée,

Elle suffit à rompre un univers dormant... ${ }^{4}$

A tradução do vous certamente influencia o modo como se interpreta o poema. Júlio Castañon Guimarães (in VALÉRY, 2013, p. 49), por exemplo, optou por traduzir o trecho anterior como segue:

Ninfas, se vós me amais, há que sempre dormir!

A menor alma, no ar, vos faz todas fremir;

Se em sua leveza a folha então se desenleia

Da sombra e, enlouquecida, aflora a napeia,

Basta para quebrar um adormecido mundo...

A tradução que propomos foi por outros caminhos, o que nos levou a traduzir o referido trecho da seguinte forma:

Ninfas! Vocês me amam? Então devem dormir!

A menor alma no ar as faz todas fremir;

Se, mesmo sendo frágil, das sombras se desloque

Uma folha perdida e roce a ninfa do bosque,

Sozinha ela rompe um universo dormente...

Como se pode notar, a terceira pessoa do plural cria uma atmosfera menos solene. Diferentemente da invocação de Deus pela serpente, na qual um "vós" atravessado de ironia foi para nós fundamental, o tratamento dado às "ninfas" - como seres de outra ordem - condiz aqui com nosso projeto de tradução. É importante assinalar que, ao longo de Charmes, há vários momentos em que o sujeito do poema se dirige a entes que habitam o mundo sobrenatural greco-latino. Essas ninfas, driades, napeias que ali se apresentam projetam o leitor para um regime de imaginação conceitual ímpar, que, de certo modo, se afasta do mundo judaico-cristão. O uso do "vocês", nesse sentido, foi um dos recursos que empregamos para não projetar essa relação no mesmo espaço enunciativo em que Deus se encontra; opção essa que se afina com a própria escolha que fizemos de traduzir "charmes" por "feitiços".

Vale lembrar que o "eu" para Valéry não é uma substância, mas um espaço relacional que funciona como pura variação. Trata-se mais de um pronome oblíquo que ganha consistência pela co-habitação em mais de uma "pessoa". Essa virtualidade encontra nas ninfas (e podemos generalizar para todo o agenciamento do mundo greco-latino por Valéry) um modo de existência muito particular: elas são uma presença, neste mundo, de outro mundo, elas são aquilo de que o poema fala e a quem o poema fala. Espécie de nó no endereçamento que implica um modo muito próprio de ser da linguagem. Ao mesmo tempo material e imaterial; memória e desejo, figura do discurso e fora do discurso. Elas são o índice desse modo de relação com a alteridade que atravessa o indivíduo para se

\footnotetext{
4 "Ninfas, se vós me amais, é preciso que sempre dormir!/ A menor alma, no ar, vos faz todas fremir;/ Mesmo, em sua fraqueza, escapada das sombras,/ Se a folha perdida toca a napeia [ninfa do bosque],/ Basta para romper um universo dormente..."

5 Cf. artigo escrito sobre o assunto.
} 
transformar em um gesto coletivo. Como no acionamento da "longue durée" do verso metrificado e rimado por Valéry elas são a sobrevivência de um mundo que se foi e que marca anacronicamente sua sobrevivência.

Esse gesto permite a Valéry o agenciamento de outro regime de historicidade. Como explica Agamben (2012) sobre as Ninfas de Aby Warburg, lidas em um viés benjaminiano, elas são a imagem da imagem (e acrescentariamos a própria possibilidade da linguagem se fazer imagem). Trata-se de um modo particular da imagem como funcionamento histórico - entre a memória e o desejo -, e que permite trabalhar "na encruzilhada entre o corpóreo e o incorpóreo, mas, sobretudo, entre o individual e o coletivo" (AGAMBEN, 2012, p. 61).

Sob o ponto de vista que analisamos aqui, na especificidade de sua sobrevivência no poema de Valéry, elas articulam a presença de uma alteridade no limiar entre o corpóreo e o incorpóreo, o individual e o coletivo, mas, também, entre a enunciação e o enunciado, elas são, pois, esse "vocês" que coloca em xeque a referência e, ao mesmo tempo, o lugar soberano do controle do enunciador sobre a sua própria enunciação. A referência se faz imagem, como rastro indicial de uma história solapada pela modernidade: há uma alteridade que enfeitiça, mas que longe de reencantar o mundo, trabalha o lado fantasmático da experiência histórica.

Ao assumir a existência dessas experiências limiares, como a própria configuração da relação eu/outro, a passagem das ninfas aciona um outro lugar que não é nem o determinismo histórico, nem o culto do novo que faz tabula rasa do passado. Poderiamos dizer com Patrice Maniglier (2006) que elas são um espaço de sobredeterminação, isto é, um lugar em que a linguagem e a experiência se deixam atravessar por mais de um modo de determinação, ou seja, uma poética, uma ética, um regime de imaginação e um regime de historicidade. Como tudo isso se cruza em ato em um poema é ainda um enigma como as ninfas, cujo mérito - e não o menor - é nos fazer conviver com o próprio enigma, ou mais, o oráculo, o mistério, o equívoco constitutivo da linguagem.

Com Gérard Dessons (1995), nessa relação entre a interlocução e a história, poderíamos dizer que as ninfas são a encarnação do funcionamento da imagem no poema, isto é, seu modo particular de significar, sua semiose específica, enfim, sua manière. Essa manière e sua raiz ambigua entre mão, manufatura, mania, é para Dessons o próprio poema e para nós um outro modo de se aproximar dos "feitiços" (ao mesmo tempo um saber-fazer e um encantamento).

Produzir, como almejamos, uma leitura de Valéry distinta daquela que predominou no Brasil - e que o viu como um poeta apenas da consciência, da construção, do cálculo, da técnica - afina-se, por exemplo, com as reflexões de Wiliam Marx (2011), para quem: "nesses tempos em que se reconhece facilmente os excessos aos quais o formalismo pode levar, às vezes, a crítica literária, a poética esotérica, lírica e epifânica de Valéry abre um caminho quem sabe salutar e que vale a pena explorar"6.

Assim, ao lado do que se chamou de formalismo, há, em Valéry, uma poética da voz, ligada ao corpo, às sensações, ao esotérico, ao epifânico e a um campo de ressonância de experiências heterogêneas no qual vibram esses entes e que Marx resume numa reveladora citação do próprio poeta:

6 No original: "En des temps où l'on reconnaît aisément les excès auxquels le formalisme a pu conduire parfois la critique littéraire, la poétique ésotérique, lyrique et épiphanique de Valéry ouvre une voie peut-être salutaire qu'il vaut la peine d'explorer". 
A operação que consiste em tirar de minha dor um canto magnífico, Essa dor estúpida conduziu meu sentido a angústias extremas, e de trevas e de fúria impotente, mas como ali não me demorei, pois subi dos infernos para poder novamente ali descer, aprendi, pelo menos, a continuidade dessa cadeia de tormentos, de esperanças e de catástrofes, e de como o mais alto ao mais baixo se interliga, toda a modulação do ser, e a conservação da vida entre os limites que ela pode transpor, - ali reside o canto, o registro. E a medida desse intervalo que é viver tem várias unidades que são ritmos.

É preciso que o canto, supremo dom, adeus supremo ao passado, eterno presente do que foi...

Voz ligada às entranhas, aos olhares, ao coração, e são esses vínculos que lhe confere seus poderes e seu sentido. Voz, elevada, tônica, tensa, fato unicamente de energia pura, livre, de alta potência, dúctil ${ }^{7}$ (VALÉRY apud MARX, 2011).

Há, pois, um modo diferente de frequentar a voz. Por meio dele acessamos outro campo de experiências: o canto, o dom, a energia, o fluxo. Nele, as ninfas estão mais presentes, nos secundam e reverberam. A multiplicação dos espaços de reverberação de experiências que desse modo se configuram ecoa em vários de seus escritos, dentre os quais merece destaque "O cemitério marinho" que trata de uma outra forma de presença da ausência: a relação com os mortos e o trabalho de luto.

\section{“O CEMITÉRIO MARINHO" - UMA SEGUNDA PESSOA EM MOVIMENTO}

Não é difícil encontrar nos comentários feitos aos poemas do livro Charmes análises que apontam para sua complexidade enunciativa. Por exemplo, como vimos, se em "Ébauche d'un serpent" há "a possibilidade de uma variação infinita dos lugares de enunciação" (ZULAR, 2014, p. 13), em "Fragments du Narcise”, seu caráter fragmentário produz multiplicidades e movências. Algo semelhante ocorre em "Le cimitière marin", comumente traduzido por "O cemitério marinho", no qual a tônica da sobrevivência - no sentido de Warburg e Didi-Huberman, Agamben e Benjamim - dos mortos e do próprio trabalho de luto permite dar vida à variação de pontos de vista. Por vida, entenda-se aqui movimento, a passagem mesma de uma imagem a outra, de um tom a outro, de um corpo a outro. Diferentemente do que pressupõe o senso comum, a ausência dos corpos, mortos, como uma espécie de valência livre da enunciação, obriga a toda uma reconfiguração do complexo enunciativo, um redimensionamento dos modos de subjetivação pela qual os sobreviventes reinventam o mundo a partir do ponto de

7 No original: "L'opération qui consiste à tirer de ma douleur un chant magnifique. Cette douleur stupide a conduit mon sens à des extrêmes détresses, et de ténèbres et de furie impuissante mais puisque je n'y suis pas demeuré, puisque je suis remonté des enfers pour pouvoir y redescendre, j'ai appris, du moins, la continuité de cette chaîne de tourments, d'espoirs et de catastrophes, et de comment le plus haut au plus bas se relie, toute la modulation de l'être, et la conservation de la vie entre les bornes qu'elle peut franchir, - c'est là le chant, le registre. Et la mesure de cet intervalle qui est vivre a plusieurs unités qui sont rythmes.

Il faut que le chant, suprême don, adieu suprême au passé, éternel présent de ce qui fut...

Voix rattachée aux entrailles, aux regards, au cœur, et ce sont ces attaches qui lui donnent ses pouvoirs et son sens. Voix, élevé, tonique, tendu, fait uniquement d'énergie pure, libre, à haute puissance, ductile". 
vista da morte, "ressoando na alma um oco sempre futuro", como traduzimos no "Cemitério marinho" (tradução ainda inédita).

Há aqui também um deslocamento contínuo do sujeito do poema pelo fluxo de alteridades que o constituem. A partir da sexta estrofe, ele começa a dialogar, em tom de invocação, com esse entorno, dirigindo-se aos céus: "Beau ciel, vrai ciel, regarde-moi qui change!" (Belo céu, verdadeiro céu, veja como mudo!). Nas estrofes seguintes, são vários os elementos com os quais o "eu" do poema segue interagindo, dirigindo-se a eles na segunda pessoa do singular: na sétima estrofe, lê-se "Je te soutiens admirable justice" (Eu te sustento admirável justiça); na nona, "Sais-tu fausse captive des feuillages [mer]" (Sabes-tu, falso cativo da folhagem [mar]); na décima-primeira, "Chienne splendide, écarte l'idolâtre!" (Cadela esplêndida, afasta o idólatra!); na décima-terceira, "Tête complète [...] Je suis en toi le secret changement" (Cabeça completa [...] Sou em ti a secreta mudança); até que se chega à décima-sétima estrofe cujos primeiros versos são:

Et vous, grande âme, espérez-vous un songe

Qui n'aura plus ces couleurs de mensonge

Qu'aux yeux de chair l'onde et l'or font ici?

Chanterez-vous quand serez vaporeuse? ${ }^{8}$

Essa mudança para a segunda pessoa do plural, no momento em que o sujeito invoca a "grande alma", provoca que tipo de reação?

Para responder a essa pergunta, faz-se necessário um pequeno excurso pelas traduções de "O cemitério marinho". Trata-se, provavelmente, do poema de Paul Valéry mais traduzido em português. No Brasil, contamos, no mínimo, com as traduções de Darcy Damasceno (1949), de Jorge Wanderley (1984), de Edmundo Vasconcelos (provavelmente de 1981), de Bruno Tolentino (2002) e de Ferreira Gullar (2014); às quais se soma ainda, pelo menos, a tradução portuguesa de Pedro José Leal (1987). Mesmo que não seja exaustivo, esse levantamento dá uma boa ideia da importância desse poema. Ao observamos esse conjunto, nota-se que as ocorrências da segunda pessoa do singular no poema de Valéry são traduzidas também pela segunda pessoa em português, ou seja, verifica-se raramente o uso do "você".

Beau ciel, vrai ciel, regarde-moi qui change!

Belo céu, vero céu, vê como eu mudo! [DAMASCENO]

Belo céu, vero céu, me transfiguro [WANDERLEY]

Belo céu, vero céu, vê me transmudo! [VASCONCELOS]

Ó belo céu, verdadeiro céu, aos poucos/vou mudando [TOLENTINO]

Céu belo e verdadeiro, olha-me eu mudo! [GULLAR]

Belo e certo céu, vê-me a ser diferente [LEAL]

8 "E vós, grande alma, esperareis um sonho/ Que não terá mais essas cores da mentira/ Que aos lhos de carne a onda e o ouro fazem aqui?/ Cantareis quando sereis vaporosa?" 
Je te soutiens admirable justice [...] Je te rends

Eu te afronto, magnífica justiça [DAMASCENO]

Detenho-me, admirável justiça da luz [VASCONCELOS]

$E$ bem defende a justiça perfeita [...] Torno-te [WANDERLEY]

Ó justiça [...] reconheço a pureza que te cabe [TOLENTINO]

Submeto-me ao justo sacrifício [...] À tua origem... [GULLAR]

Eu vou a sustentar-te, justiça assombrosa [LEAL]

$* * *$

Sais-tu fausse captive des feuillages

Sabes-tu, prisioneiro das folhagens [DAMASCENO]

O Falso prisioneiro da folhagem [...] Vês [WANDERLEY]

Sabes, falso cativo das ramagens [VASCONCELOS]

Falso cativo das folhagens, mar/ que róis [TOLENTINO]

Tu sabes, prisioneiro das folhagens [GULLAR]

Enganoso escravo de tanta folhagem [...] Que corpo me arrasta a seu preguiçoso fim [LEAL]

Chienne splendide, écarte l'idolâtre!

Cadela esplêndida, afugenta o idólatra! [DAMASCENO]

Cão esplendente, afasta adoradores! [WANDERLEY]

Esplêndido molosso, afasta o idólatra [VASCONCELOS]

Cão esplêndido, espanta a idolatria! [TOLENTINO]

Esplêndida cadela, ao adorador/ Espanta [GULLAR]

Esplêndida cadela, arreda o idólatra! [LEAL]

Je suis en toi le secret changement

Eu sou em ti a recôndita mudança [DAMASCENO]

Eu sou em ti a secreta alteração [WANDERLEY]

Eu sou em ti a secreta mutação [VASCONCELOS]

sou eu o vinco em tua testa, a ruga [TOLENTINO]

Sou em ti uma mudança oculta [GULLAR]

Quero em ti dizer a secreta inconstância [LEAL]

Como se pode observar, as únicas exceções se dão em pouquíssimos momentos, mas nunca pela substituição da segunda pessoa do singular pela segunda do plural. Curiosamente, não é o que acontece na direção contrária, ou seja, quando se trata, na décima-sétima estrofe, de traduzir o vous, a maioria esmagadora dos tradutores optou pelo "tu". 
Et vous, grande âme, espérez-vous un songe

E tu, grande alma, acaso um sonho esperas, [DAMASCENO]

$E$ tu, grande alma, por um sonho esperas? [WANDERLEY]

E vós, grande alma, esperais um sonho [VASCONCELOS]

E tu, minh'alma? Esperas algum dia [TOLENTINO]

E tu, grande alma, ao que enfim aspiras? [GULLAR]

$E \mathrm{tu}$, grande alma, esperarás um sonho [LEAL]

Um único tradutor, de fato, optou por manter o "vós". Trata-se de Edmundo Vasconcelos, autor de uma singular tradução. Nela, apresenta as estrofes acompanhadas de comentários. Sobre a estrofe XVII discorre:

É um diálogo com os mortos e a alma. A "grande alma", expressão que foi considerada por alguns comentadores como uma ironia metafísica, não me parece tal, mesmo porque seria totalmente sem sentido e deslocada.

[...]

A interpretação, parece-me, é uma interrogativa às grandes almas, às almas iluminadas, se ainda crêem no sonho da imortalidade. Maomé, São João da Cruz, Çakia-Muni.

(in VALÉRY, s.d., p. 96)

Ainda que as razões de Edmundo Vasconcelos possam ser controversas, é certo que ele, de modo consciente, opta pelo registro elevado com o intuito de, assim como faz Valéry, estabelecer uma distância maior em relação à "grande alma". Os outros tradutores brasileiros, talvez porque, como já apontamos o próprio "tu" já seja, entre muitos de nós, bastante elevado, tenha preferido, nesse caso, padronizar o tratamento dado aos entes invocados.

Chama especial atenção que, na edição portuguesa, Pedro José Leal também tenha preferido a segunda pessoa do singular, sobretudo se levarmos em conta a permanência do "vós" nos usos do português europeu. Como observa Evanildo Bechara (2001, p. 166): "ainda continuam em Portugal vós, vosso". Essa opção do tradutor português parece indicar que, nesse caso, a aproximação ou o distanciamento em relação à "grande alma" não lhe pareceu tão relevante.

Em nosso caso, preferimos, uma vez mais, explorar a tensão tu/vous, altamente produtiva no complexo enunciativo dos poemas de Paul Valéry. Basta retomar os poemas em conjunto, para vermos quanto o que está em jogo nessa passagem é a desarticulação de uma voz soberana que subssumisse todas as outras posições (como acontece no "vous" da voz de Deus no "Esboço de serpente". Traduzimos, pois, em "O cemitério marinho", todas as ocorrências de "tu" pela segunda pessoa do singular e o "vous" da "grande âme", pela segunda pessoa do plural, tentando manter um tom mais próximo da ironia desconstrutiva dessa voz majestática, o que fica evidente na brutal mudança de tom nos dois últimos versos da estrofe:

E vós, grande alma, tendes ainda um sonho em mira

Que já não mais terá as cores de mentira

Que aos olhos de carne a onda e o ouro ainda têm? 
E cantareis quando vós fordes vaporosa?

Vai! Tudo foge! Minha presença é porosa,

A santa impaciência há de morrer também!

\section{O COMPLEXO ENUNCIATIVO COMO ESPAÇO DE VARIAÇÃO}

Como procuramos demonstrar ao longo deste trabalho, as diferenças existentes entre os usos dos pronomes pessoais em francês e em português abrem múltiplas possibilidades para a tradução da segunda pessoa, especialmente do vous em português. Esse amplo leque levou, por exemplo, Paulo Rónai (1983, p. 177), em seu Guia prático da tradução francesa, a declarar que o Vous:

É palavra das mais comuns, cuja tradução, porém, requer cuidado especial. Empregado ora como sujeito, ora como objeto direto ou indireto, esse pronome pode referir-se a uma ou mais pessoas. Só o contexto determina se na frase Je ne vous connais pas se deve traduzir vous por "você", "vocês", "vos", "o", "a", "os", "as", "o senhor", "a senhora”, "os senhores", "as senhoras” ou mesmo "te”.

No caso de Charmes, a questão dos contextos se torna ainda mais sensivel, pois, como se pode notar, as escolhas implicam uma determinada leitura do poema, na qual a ênfase em certos aspectos, como as escolhas pronominais, pode levar o leitor a aproximar-se ou distanciar-se das imagens e conceitos ali presentes. Costumamos pensar no "eu" que aparece no enunciado, mas pouco na relação que ele estabelece com os interlocutores; no entanto, esse espaço de interlocução é a condição mesma de existência de algo como um "eu". Nos poemas de Valéry, no entanto, essa relação, como nos casos do "tu" e do "vous", é decisiva para que se configure o lugar de enunciação. Mais do que isso, como não há um "eu" anterior à situação de enunciação, o que vemos é um processo de variação contínua, mais ou menos coerente, conforme o caso. O que importa é a flutuação dessas relações em que vamos continuamente nos deslocando por variações sutis que são a própria potência dos modos de subjetivação na e com a linguagem.

Essa precedência do "tu", do outro, é constitutiva do modo de conceber a linguagem e a poética de Valéry. Trata-se, como se vê, de uma questão ética em que não está em jogo apenas que o "eu é um outro", mas que o outro é um "eu", isto é, de que somos habitados por outras subjetividades que nos atravessam. $\mathrm{O}$ endereçamento é o modo de ser do outro em mim. Como se só houvesse "mim" como um espaço relacional entre o "eu" e o "tu" ou "vós".

Trata-se de saber a quem dizemos "eu", isto é, a quem atribuímos esse eco subjetivo que nos constitui. Da pessoa amada, a Deus, às Ninfas, ao Céu, forçamos os limites da linguagem para além dela mesma. Somos falados por esses seres a quem nos endereçamos. O endereçamento já seria o lugar de enunciação, não fosse o fato de não haver "um" lugar, mas uma relação que constitui em sua movência a beleza dos atos de fala.

O fluxo dos atos de fala constitui à sua maneira a manière, para retomarmos mais uma vez Gérard Dessons (1995). Isto é, eles se dão no contínuo da linguagem, mas não por uma ontologia negativa, uma metafísica do indizivel (do invisível ou do inaudivel), mas por um outro modo de configurar a relação entre o 
dizivel e o indizivel. É ao habitar esse espaço de inter-relação (que é também o espaço entre o "eu" e o "outro") que o fazer se faz uma maneira. A maneira é um atravessamento entre linguagem e matéria, ato e sentido que é a própria aventura da significação como lugar de passagem de uma geração a outra em um contínuo que sempre escapa ao já conhecido.

Não se trata de nomear a essência, o ser ou Deus, não se trata sequer de um problema de nomeação, mas de acionar a dialogicidade equívoca da linguagem e do poema que nos permite ocupar mais de uma posição, mais de um modo de existência. Essa variação - a "self-variation" - como mostra Nicole Celeyrette-Pietri (1979) no clássico Valéry et le moi, é a própria possibilidade de se dizer "eu", pronome já marcado em Valéry pela obliquidade equivoca - a diferença do eu consigo mesmo - de um "moi". É entre esse "eu" e o "mim" que a enunciação se abre para uma alteridade radical como espaço de experiência de outros modos de existência.

Quando um projeto de tradução é levado a cabo por dois tradutores, essa obliquação dos pronomes e das pessoas no poema, para usarmos os termos de Alexandre Nodari (2017), torna-se a matéria mesma do processo, pois não há apenas "um" que fala, mas uma fala que é sempre atravessada por "mais de um", como se a variação das pessoas se tornasse, no nosso caso, o próprio vir a ser do processo tradutório. Enfim, como qualquer tradução, a nossa também é marcada por sua historicidade. Em tempos em que a complexidade e a heterogeneidade têm sido consideradas noções importantes para pensar o mundo contemporâneo, optamos por explorar, ao logo dos poemas de Charmes, distintas possibilidades de tradução do tu e do vous; opções essas que, longe de esgotar qualquer possibilidade, evidenciam a força do campo da retradução como espaço de variação: um campo profícuo para a reflexão sobre o alcance e as reverberações de modos de existência.

\section{Variations of the second person in the translation of Charmes by Paul Valéry}

Abstract: This article aims to discuss some of the translation choices involving the use of the pronouns tu and vous in the poems of Paul Valéry's Charmes, which we are currently translating. In this analysis we take into account the different uses of personal pronouns in French and Portuguese, as well as the specificities involved in each of the poems chosen in this article to illustrate the choices. When possible, we compare the choices made by us with those of other translators.

Keywords: Paul Valéry. Poetic translation. Personal pronouns.

\section{REFERÊNCIAS}

AGAmBen, G. Ninfas. São Paulo: Hedra, 2012.

ALMEIDA, G. Poetas de França. 4. ed. São Paulo: Cia. Editora Nacional, 1965. ASCHER, N. Poesia alheia. Rio de Janeiro: Imago, 1998.

BECHARA, E. Moderna gramática portuguesa. Rio de Janeiro: Lucerna, 2001. 
BORBA, F. Dicionário do português contemporâneo. São Paulo: Editora Unesp, 2004.

CELEYRETTE-PIETRI, N. Valéry et le moi. Des Cahiers à 1'oeuvre. Paris: Klencksieck, 1979.

CHARAUDEAU, P. Grammaire du sens et de l'expression. Paris: Hachette, 1992.

DESSONS, G. La manière est le poème même. Littérature, n. 100, p. 81-91, 1995. Disponivel em: <http://www.persee.fr/docAsPDF/litt_0047-4800_1995_ num_100_4_2386.pdf>. Acesso em: 25 out. 2017.

GULLAR, F. O prazer do poema: uma antologia pessoal. Rio de Janeiro: Edições de Janeiro, 2014.

MANIGLIER, P. La vie énigmatique des signes. Paris: Léo Scheer, 2006.

MARX, W. Les deux poétiques de Valéry. In: Paul Valéry et l'idée de littérature. 2011. Disponivel em: <http://www.fabula.org/colloques/document1426.php>. Acesso em: 25 out. 2017.

NEVES, M. H. de M. Gramática de usos do português. São Paulo: Editora Unesp, 2000.

NODARI, A. Alterocupar-se: obliquação e transicionalidade ontológica. Disponível em: <https://pt.scribd.com/document/356165810/Alterocupar-se-obliquacao-e-transicionalidade-ontologica>. Acesso em: 1º jul. 2017.

RÓNAI, P. Guia prático da tradução francesa. Rio de Janeiro: Nova Fronteira, 1983.

TOLENTINO, B. O mundo como ideia. São Paulo: Globo, 2002.

VALÉRY, P. O cemitério marinho. Tradução Darcy Damasceno. Rio de Janeiro: Orfeu, 1949.

VALÉRY, P. Oeuvres I. Paris: Gallimard, 1957.

VALÉRY, P. Oeuvres II. Paris: Gallimard, 1960.

VALÉRY, P. O cemitério marinho. Tradução Jorge Wanderley. São Paulo: Max Limonad, 1984.

VALÉRY, P. Variedades. Organização João Alexandre Barbosa. Tradução Maiza Martins de Siqueira. São Paulo: Iluminuras, 1991.

VALÉRY, P. Fragmentos do Narciso e outros poemas. Tradução Júlio Castañon Guimarães. São Paulo: Ateliê, 2013.

VALÉRY, P. O cemitério marinho. Tradução Edmundo Vasconcelos. São Paulo: Massao Ohno-Roswita Kempf, s. d.

VEIGA, C. Gramática nova do francês. São Paulo: Editora do Brasil, 1974.

ZULAR, R. O ouvido da serpente. In: PASSOS, C. R.; ROSENBAUM, Y. (Org.). Interpretações. Crítica Literária e Psicanálise. São Paulo: Ateliê, 2014.

Recebido em julho de 2017. Aprovado em setembro de 2017. 